$\underline{\text { Research Article }}$

\title{
Farmers' occupational health, perception and practices towards leptospirosis: A cause for concern
}

\author{
J Mathanamohan $^{1}$, F Kaleel ${ }^{1}$, H Hyderaly ${ }^{1}$, I Imthiyaz ${ }^{1}$, R Unais ${ }^{1}$, T Nisansala ${ }^{1}$, M Weerasekera ${ }^{1}$, \\ N Fernando ${ }^{1}$, T Liyanage ${ }^{2}$, C Gunasekara $^{1}$
}

Sri Lankan Journal of Infectious Diseases 2020 Vol.10 (1):21-29

DOI: http://dx.doi.org/10.4038/sljid.v10i1.8247

\begin{abstract}
Introduction: Leptospirosis is a neglected zoonotic disease with a global distribution. Exposure to Leptospira is a major occupational health concern with farmers. Lack of awareness of disease can result in delay in seeking medical care which has serious implications on morbidity and mortality. This study aimed to assess knowledge, attitudes and practices (KAP) towards leptospirosis among farmers in the district of Colombo, Sri Lanka.

Methods: The study was a descriptive, cross sectional study conducted among farmers in the district of Colombo, Sri Lanka. Data was collected using a pre-tested interviewer-administered questionnaire to assess the KAP of 120 randomly selected farmers in the Homagama, Padukka, Boralesgamuwa and Kotte Medical Officer of Health (MOH) areas.

Results: The majority of respondents were in the 50-74 year age group and $85 \%$ were male. The majority of participants had reasonable knowledge (74\%) of the method of transmission, symptoms, complications and preventive measures of leptospirosis, which was occupationally related to farming. Satisfactory attitudes towards disease prevention was demonstrated by $92.5 \%$ and $53.3 \%$ had favorable practices.
\end{abstract}

Conclusion: The results of the study imply that knowledge of leptospirosis among the farming community can be improved further. This in turn may help to translate toward better attitudes and practices.

Keywords: Attitudes, Knowledge, Leptospirosis, Practices

${ }^{1}$ Department of Microbiology, Faculty of Medical Sciences, University of Sri Jayawardenepura, Sri Lanka ${ }^{2}$ Department of Community Medicine, Faculty of Medical Sciences, University of Sri Jayawardenepura, Sri Lanka

Address for correspondence: Dr Chinthika Gunasekara, Department of Microbiology, Faculty of Medical Sciences, University of Sri Jayawardenepura, Gangodavila, Nugegoda, Sri Lanka Telephone: + 0094718262860

Email: chinthika@sjp.ac.lk (iD) https://orcid.org/0000-0002-6003-3088

Received 13 May 2019 and revised version accepted 20 November 2019

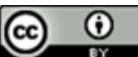

This an open-access article distributed under the terms of the Creative Commons Attribution License, which permits unrestricted use, distribution, and reproduction in any medium, provided the original author and source are credited. 


\section{Introduction}

Leptospirosis is an endemic zoonotic disease of public health importance in Sri Lanka. Large outbreaks of leptospirosis have been reported in Sri Lanka during the paddy cultivation season. The disease is transmitted by mammalian vectors including rodents and cattle and is a major occupational health concern among farmers. ${ }^{1}$ Seasonal outbreaks of leptospirosis occur annually. In 2016, 3982 suspected cases of leptospirosis and 62 deaths were reported to the Epidemiological unit of Sri Lanka, including 290 suspected cases from the district of Colombo. ${ }^{2}$ The case fatality ratio was $1.56 \%$. The Ministry of Health, Sri Lanka has taken measures to improve public awareness of leptospirosis and to encourage farmers, who are an occupational risk group, to seek prophylaxis and early treatment. ${ }^{3}$ The disease is a notifiable disease in the country.

Early detection can contribute considerably to recovery with good outcomes due to availability of antibiotic therapy and appropriate management. ${ }^{4}$ Unfortunately in Sri Lanka, there is a delay in patients seeking medical attention at an early stage. ${ }^{5}$ This may be due to insufficient knowledge and poor attitudes and practices towards leptospirosis. A recent systematic review of the burden of leptospirosis in Sri Lanka showed that the disease is grossly underestimated and the true burden of disease within the country is cannot be ascertained due to lack of accurate data reporting. ${ }^{6}$ Since the disease is highly endemic and carries a high morbidity and mortality, it is imperative to investigate the knowledge, attitudes and practices regarding leptospirosis, and awareness regarding prevention of the disease among farmers who are the primary risk group.

\section{Materials and Methods}

\section{Study setting}

The study was a descriptive cross-sectional study conducted among farmers in four randomly selected $\mathrm{MOH}$ areas, namely Homagama, Padukka, Boralesgamuwa and Kotte in the district of Colombo (Figure 1). The district of Colombo has an estimated total population of $2,324,349$ with 34,391 population of farmers. The estimated population of the MOH areas of Homagama, Padukka, Borelesgamuwa and Kotte are 229,332, 61,977, 54,701 and 61,311, respectively. The farming population of those four $\mathrm{MOH}$ areas are 9,319, 6,220, 3,010 and 227 , respectively.

\section{Study sample (inclusion criteria)}

The study population consisted of farmers involved in paddy farming from the month of May to August, coinciding with the paddy cultivation season. One hundred and twenty

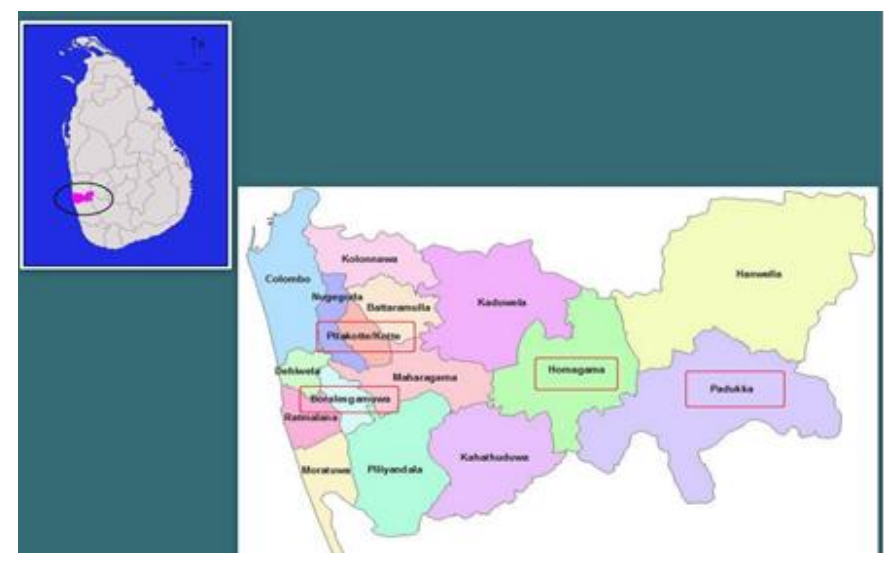

Figure 1: A map of the district of Colombo showing the MOH areas of the district.

The district of Colombo is located within the circle of the map of Sri Lanka positioned in the left upper corner of the figure. In the map of Colombo, the relevant $\mathrm{MOH}$ areas are highlighted in red. 
farmers who had engaged in paddy cultivation for a period of one year or more were included. The sample size was calculated with a 95\% confidence interval and 9\% margin of error. The sample was divided among four $\mathrm{MOH}$ areas according to the probability proportionate to the size of the population of each $\mathrm{MOH}$ area. From the farmer's list of the individual $\mathrm{MOH}$ areas, the first person was chosen randomly using the lottery method and every third person on the list was selected thereafter until the required sample size was reached.

\section{Study instruments}

The knowledge, attitudes and practices of the farmers towards leptospirosis were assessed using a pretested interviewer administered questionnaire. The questionnaire was pre-tested on a representative sample of 30 respondents as a pilot study and the questions modified where necessary to improve clarity. The questionnaire consisted of demographic information (gender, age, education and occupation), and questions on knowledge (transmission, symptoms, complications, preventive and safety measures), attitudes (self-perceived risk and seeking medical care) on leptospirosis and practices for disease prevention (protective methods and prophylaxis).

\section{Data analysis}

The data was analyzed using the SPSS (Statistical Package for Social Sciences) software version 16.0. A knowledge, attitude and practice score was calculated based on mean scores of each section. For each section the total score for knowledge, attitudes and practices were calculated for each individual separately. The mean score for knowledge was obtained by adding the total scores under knowledge of all individuals and dividing by the number of individuals. The mean score for attitudes and practices were calculated similarly.

With regard to knowledge, a score of $\geq 75 \%, 50-74 \%$ and $<50 \%$ was considered good, satisfactory and poor respectively. ${ }^{7}$ Attitudes and practices on leptospirosis were assessed using a Likert's scale. The mean score was calculated for attitudes and practices. For attitudes $\geq 70 \%$ was considered as satisfactory and $<70 \%$ unsatisfactory, while $\geq 60 \%$ was considered as satisfactory and $<60 \%$ unsatisfactory for practices.

The Wilcoxon rank test was used to test the differences between education groups in knowledge, attitudes and practices on leptospirosis within the study population.

\section{Results}

The study included 120 subjects with a response rate of $100 \%$. Socio demographic characteristics of the study population are presented in Table 1 .

Of the total of 120 farmers, 49 (40.8\%) were from Homagama, 35 (29.2\%) from Padukka, 22 (18.3\%) from Boralasgamuwa and $14(11.7 \%)$ from Kotte. Fifty percent $(50.8 \%)$ of the respondents were between the age group of 50 to 74 years and $85 \%$ of the respondents were males. A total of $63(52.5 \%)$ were involved only in agricultural activities while the remaining 57 (47.5\%) engaged in different occupations in addition to agricultural activities. 
Table 1: Socio demographic characteristics of the study population

\begin{tabular}{llcc}
\hline Socio-demographic character & $\begin{array}{c}\mathbf{n} \\
(\mathbf{n = 1 2 0})\end{array}$ & $\mathbf{\%}$ \\
\hline \multirow{3}{*}{ Age group } & 18-24 years & 3 & 2.5 \\
& 25-49 years & 54 & 45 \\
& 50-74 years & 61 & 50.8 \\
& >75 years & 2 & 1.7 \\
\hline \multirow{2}{*}{ Gender } & Male & 102 & 85 \\
& Female & 18 & 15 \\
\hline \multirow{2}{*}{ Education level } & Primary education & 7 & 5.8 \\
& Secondary education & 102 & 85 \\
& Tertiary education & 11 & 9.2 \\
\hline
\end{tabular}

\section{Knowledge}

The farmers were questioned on several aspects of knowledge on transmission, symptoms, complications and preventive measures. The responses are presented in Table 2. Almost all had heard of leptospirosis, commonly known as rat fever $(96.7 \%, \mathrm{n}=116)$, the main sources of information being the public health inspector (PHI) visits (89.2\%), television (61.7\%) and leaflets that are distributed by the Ministry of Health (57.5\%). Of the respondents, 65.8\% thought they were at risk. More than half the respondents had heard of a recent case of leptospirosis in the area.

Although traditionally known as "rat fever", participants were able to identify other mammals such as cows, buffaloes (70.8\%) and dogs (72\%) as vectors. Rats were identified as transmitters by $85.8 \%$ of respondents. They also identified the paddy cultivation seasons $(75 \%)$ and rainy (52\%) and harvesting seasons (50\%) as important periods for transmission of this disease. Farmers knew that leptospirosis was an occupational hazard and 80.8\%, 67.5\%, 69.2\% respectively were able to identify paddy fields, marshy lands and animal urine as sources of infection with $89.2 \%$ identifying working in paddy fields as a risk activity. However, most respondents failed to identify other important sources such as exposure to flood water, ponds, rivers and pools and recreational activities such as swimming as risk factors.

Most respondents (95\%) correctly stated damaged skin as a route of infection. With regard to symptoms and complications of leptospirosis, most respondents identified fever (98.3\%) and muscle pain $(84.2 \%)$ as symptoms. Further, $75 \%$ were aware it could cause organ damage including kidney damage $(73.3 \%)$. More than $90 \%$ of the respondents knew that rat fever could be treated and $81.7 \%$ knew that rat fever could be fatal.

Of knowledge on preventive measures, the majority were aware that prophylactic medication could prevent rat fever. Almost all knew of the availability of prophylaxis and the majority (61.7\%) said they could get prophylaxis from the $\mathrm{MOH}$ office. Sixty five $(65.8 \%)$ of the farmers knew rodent control was a preventive measure for leptospirosis in the community. When individual responses were considered, a good number of the respondents (74\%) had satisfactory knowledge of leptospirosis. 
Among the study group, there was no significant difference $(\mathrm{p}=0.4105)$ in the level of knowledge of leptospirosis in famers with differing educational levels (primary, secondary and tertiary).

Table 2: Knowledge regarding leptospirosis

\begin{tabular}{|c|c|c|}
\hline $\begin{array}{l}\text { Aspect of knowledge on } \\
\text { leptospirosis }\end{array}$ & $\begin{array}{c}\mathbf{n} \\
(\mathbf{n}=\mathbf{1 2 0})\end{array}$ & $\%$ \\
\hline \multicolumn{3}{|l|}{ Method of transmission } \\
\hline Rats & 103 & 85.8 \\
\hline Dogs & 87 & 72.5 \\
\hline Cows and Buffaloes & 85 & 70.8 \\
\hline \multicolumn{3}{|l|}{ Sources } \\
\hline Flood Water & 51 & 42.5 \\
\hline Paddy fields & 97 & 80.8 \\
\hline Marshy Lands & 81 & 67.5 \\
\hline Vegetation & 64 & 53.3 \\
\hline Ponds, rivers and pools & 41 & 34.2 \\
\hline Moist soil & 59 & 49.2 \\
\hline Animal Urine & 83 & 69.2 \\
\hline \multicolumn{3}{|l|}{ Symptoms } \\
\hline Fever & 118 & 98.3 \\
\hline Muscle pain & 101 & 84.2 \\
\hline Headache & 93 & 77.5 \\
\hline Yellowish discoloration of skin & 65 & 54.2 \\
\hline \multicolumn{3}{|l|}{ Complications } \\
\hline No complications & 9 & 7.5 \\
\hline Kidney Damage & 88 & 73.3 \\
\hline Liver Damage & 68 & 56.7 \\
\hline Pneumonia & 50 & 41.7 \\
\hline \multicolumn{3}{|l|}{ Preventive measures } \\
\hline Vaccination of domestic dogs & 38 & 31.7 \\
\hline $\begin{array}{l}\text { Taking rat fever medication } \\
\text { during paddy season }\end{array}$ & 108 & 90.0 \\
\hline $\begin{array}{l}\text { Wearing boots and gloves when } \\
\text { working outdoors }\end{array}$ & 75 & 62.5 \\
\hline $\begin{array}{l}\text { Covering open cuts and wounds } \\
\text { when working outdoor }\end{array}$ & 98 & 81.7 \\
\hline Rodent control & 99 & 82.5 \\
\hline $\begin{array}{l}\text { Boiling water (taken from } \\
\text { natural sources) before drinking }\end{array}$ & 92 & 76.7 \\
\hline Draining areas with stagnant water & 95 & 79.2 \\
\hline
\end{tabular}

\section{Attitudes towards leptospirosis}

Good attitudes regarding disease prevention can lead to good practice. Table 3 shows the percentage of respondents with correct attitudes towards leptospirosis. In this study, $87.5 \%$ of the respondents believed that leptospirosis is a deadly disease and $97.5 \%$ of the respondents were of the attitude that they should immediately seek medical attention if leptospirosis is suspected. 
Table 3: Attitude towards leptospirosis

\begin{tabular}{lc}
\hline Attitudes & $\begin{array}{c}\text { Yes (\%) } \\
(\mathrm{n}=120)\end{array}$ \\
\hline Leptospirosis is a deadly disease * & 87.5 \\
\hline I think leptospirosis needs more control and prevention than currently practiced* & 87.5 \\
\hline I think it is important to seek immediate medical attention if I suspect leptospirosis* & 97.5 \\
\hline I am not bothered about getting leptospirosis as I am not at risk & 26.6 \\
\hline I think controlling rat population is necessary in controlling transmission of leptospirosis* & 81.6 \\
\hline I think wearing proper gloves and boots when working in the field is necessary in & 71 \\
controlling transmission of leptospirosis & \\
\hline I think covering wounds is necessary in controlling transmission of leptospirosis* & 87.5 \\
\hline I think prophylaxis is effective* & 85 \\
\hline I have already got leptospirosis once, so I am not at risk again & 43.3 \\
\hline *Indicates the correct positive attitude &
\end{tabular}

Only 26.6\% thought they were not at risk of acquiring leptospirosis while $43.3 \%$ respondents believed that once they got the disease, it provided lifelong immunity. Most respondents (81.6\%) believed that controlling the rat population was necessary to prevent transmission of leptospirosis. Although $71 \%$ of the farmers believed that wearing proper gloves and boots when working in the field was helpful, only $18.3 \%$ and $21.7 \%$ respectively wore boots and gloves (Table 4) as they found it cumbersome. While $87.5 \%$ thought that covering wounds is necessary as a preventive measure for leptospirosis, a large percentage (85\%) felt that prophylaxis is an effective factor for preventing the disease. Judging by the responses, most of the respondents (92.5\%) had good attitudes about the disease.

There was no significant difference in attitudes between study participants of different educational levels in the study $(\mathrm{p}=0.4022)$.

\section{Practices for prevention of leptospirosis}

Good practice is imperative for controlling transmission of disease. Table 4 describes the practices of the study population. Only $18.3 \%$ and $21.7 \%$ respondents claimed to wear boots and

Table 4: Practices for prevention of leptospirosis

\begin{tabular}{|l|c|}
\hline Practices & $\begin{array}{c}\text { Yes (\%) } \\
\text { (n=120) }\end{array}$ \\
\hline I wear boots when working in the fields & 18.3 \\
\hline I wear gloves when working in the field & 21.7 \\
\hline I cover open wounds prior to working in the field & 92.5 \\
\hline I take doxycycline prophylaxis properly & 59.2 \\
\hline I immediately seek medical attention when I & 84.2 \\
\hline come down with a fever & \\
\hline I use traps as a form of rodent control & 59.1 \\
\hline I use bait as a form of rodent control & 42.5 \\
\hline
\end{tabular}

gloves respectively because wearing them is cumbersome. A vast majority $(92.5 \%)$ of the respondents claimed that they cover open wounds prior to working in the fields. More than half $(59.2 \%)$ of the respondents claimed that they take doxycycline prophylaxis properly. However, nearly 50\% participants acknowledged taking traditional medicine as a first cure for fever which is

potentially a risky practice. Methods used for rodent control included traps $(59.1 \%)$ and use of bait $(42.5 \%)$. In this study, many recommended practices for prevention of leptospirosis were practiced by only just over half the respondents $(53.3 \%)$. 
There was no significant association between education levels of the study participants and their practices for prevention of leptospirosis $(\mathrm{p}=0.9572)$.

\section{Discussion}

The Colombo district is in the western province of Sri Lanka in the wet zone of the country. The annual rainfall is around $2,500 \mathrm{~mm}$ and temperatures vary from $22{ }^{\circ} \mathrm{C}$ to $31{ }^{\circ} \mathrm{C}$. Rainfall is experienced in Colombo during monsoon seasons from May to August and October to January where paddy farming is carried out during those two seasons. According to epidemiological reports, the trend of leptospirosis notification follows a seasonal variation linked with paddy cultivation and harvesting.

Improved awareness and knowledge is critical in controlling leptospirosis among high risk populations. In Sri Lanka paddy cultivators are regarded as a high-risk occupational group who are designated for prophylactic antibiotic therapy.

This study reveals a satisfactory knowledge on transmission, prevention and symptoms of leptospirosis among a representative sample of cultivators from the Colombo District. A household survey conducted by Agampodi et $\mathrm{al}^{8}$ among farmers from 14 districts, including the Colombo district, has previously shown similar findings with a satisfactory level of knowledge of symptoms of leptospirosis and awareness of chemoprophylaxis. Although the risk of acquiring leptospirosis is high among farmers, Sarwankar et al (2017) reported that other occupational categories such as slaughterhouse workers, slum residents, outdoor/ sewer workers, veterinarians, dairy workers, and military personnel are at high risk of getting the disease. ${ }^{9}$ A high percentage of leptospirosis awareness was reported from agricultural and non-agricultural workers in the Philippines $(87.27 \%)^{10}$ and urban slum residents in Brazil $(90.3 \%)$. Very poor leptospirosis awareness from abattoir workers in North Central Nigeria was reported with no knowledge of the disease at all (95.8\%). ${ }^{12}$ Importantly, local government health units and mass media are powerful tools in generating better awareness about leptospirosis in other studies ${ }^{10,13}$, whereas visits by public health inspectors, television and leaflets were important locally in knowledge dissemination about leptospirosis.

This study sample suggested an improved level of knowledge on the transmission of leptospirosis compared with previous studies. In a national household survey of leptospirosis conducted in Sri Lanka, knowledge on the reservoirs was mainly restricted to rat and other rodents, while the study population failed to identify that cattle, buffalo and dogs also harbor the infection. ${ }^{8}$ Despite the fact that leptospirosis is traditionally called 'rat fever' in the community, correct identification of other vectors as source of infection in our study population is a promising finding. This may be due to better awareness among farming communities in the Colombo district.

The study sample in the current study were able to identify the common clinical symptoms of leptospirosis such as fever, muscle pain and headache. This finding was remarkable when compared to previous studies as a high proportion of the study population correctly identified the symptoms of leptospirosis. ${ }^{8,11}$ Although the majority of the study population in the study by Agampodi and colleagues ${ }^{8}$ identified fever as a clinical symptom, association of the other common clinical findings were not satisfactory. Nearly three quarter of the respondents in the current study were aware that leptospirosis can cause multi organ failure, with most mentioning 
kidney damage as the commonest complication, followed by liver damage. In contrast, in previous studies, although renal problems were identified, the association of leptospirosis with hepatic and pulmonary complications was not generally recognized by farmers. ${ }^{8,11}$ This is an important finding as correct identification of the symptoms and knowledge of the adverse sequelae would prompt patients to seek immediate medical attention.

Knowledge of preventive measures is another important aspect. Although it is known that there is an uncertain advantage in reducing incidence of leptospirosis with doxycycline prophylaxis, $200 \mathrm{mg}$ of oral doxycycline prior to farming activities has been advocated as a preventive measure. ${ }^{14}$ In Sri Lanka, antibiotic prophylaxis is freely available through the MOH offices to those engaging in farming activities. Most study participants $(94.0 \%)$ knew of a prophylaxis, and $90 \%$ pointed out that taking prophylaxis is an important means of prevention. This highlights the importance of knowledge of chemoprophylaxis and the fact that $90 \%$ were aware of this is an important indicator of effective communication to an 'at risk' population.

The first step towards reducing the incidence of leptospirosis is the realization of the risk (73.4\%), which in turn helps in better practices. Only about half the population correctly believed that a single attack of leptospirosis does not provide lifelong immunity. An individual who has had leptospirosis once may be more likely to be careless where prevention is concerned.

Knowledge alone of preventive measures is of less significance if the individuals do not adopt the recommended practices. Although a majority (70.8\%) believed that wearing boots and gloves when working in the fields was an important control measure, a considerable number (63\%) believed that this personal protective equipment is too cumbersome for routine use. This result, however, is better than what was observed in a study conducted among municipal workers in India, where the respondents believed that wearing boots $(88 \%)$ and gloves $(85 \%)$ cause discomfort. ${ }^{15}$ Regardless, this was a practical finding that reflects difficulties in establishing feasible preventive measures in the population at risk.

A limitation of the study is that this was not based on real time observation of actual practices, which would have provided a more valid assessment of preventive practices. However, this study provides an insight into the knowledge, attitudes and practices and identifies gaps which need to be addressed for effective prevention of leptospirosis in the farming community. The findings of this study identify the need for conducting regular training programs to raise awareness among the risk groups and general population about leptospirosis. School awareness programs in high risk areas for both parents and students could further contribute to increased awareness and better practices.

\section{Conclusion}

In conclusion, although good knowledge, attitudes and practices were found in the study community, there were some gaps in knowledge of the source and mode of transmission, symptoms, complications, risk factors, personal protective equipment usage and prophylaxis which may affect the level and frequency of correct preventive practices. Awareness must be initiated at an individual level and increased to improve effective preventive measures for successful prevention and control of leptospirosis. Implementation of regular training programs to raise awareness among the farming community and distribution of information leaflets is important to raise awareness and thus improve good practices. 
Acknowledgment: We wish to acknowledge all farmers who participated in this study.

Conflict of interest: There are no conflicts of interest.

Ethical statement: Ethical clearance for the study was obtained from the Ethics Review Committee of the University of Sri Jayewardenepura, Sri Lanka (ERC application No.17/15). Informed written consent was obtained from each participant prior to enrollment.

\section{References}

1. Victoriano AFB, Smythe LD, Gloriani-Barzaga N, et al. Leptospirosis in the Asia Pacific region. BMC Infect Dis. 2009; 9(1):147 doi:10.1186/1471-2334-9-147

2. Epidemiology Unit, Ministry of Health, Nutrition \& Indigenous Medicine. Weekly Epidemiology Report. 2017; 44(1):2.

3. Denipitiya D, Chandrasekharan N, Abeyewickreme W, et al. Application of a real time polymerase chain reaction (PCR) assay for the early diagnosis of human leptospirosis in Sri Lanka. Biologicals. 2016; 44(6):497-502. doi: 10.1016/j.biologicals.2016.09.004

4. Haake DA, Levett PN. Leptospirosis in humans. Leptospira and leptospirosis: Curr Top Microbiol Immunol 2015. p. 65-97. doi: 10.1007/978-3-662-45059-8_5.

5. Nisansala, T., Bandara, K., Weerasekera, M., et al. Manifestations and outcomes of leptospirosis during local outbreaks in high endemic districts of Sri Lanka: A retrospective multi-center study. Asian Pac J Trop Med, 2019; 12(10):442-449 doi: 10.4103/1995-7645.269904

6. Warnasekara, J., Koralegedara, I., Agampodi, S. Estimating the burden of leptospirosis in Sri Lanka; a systematic review. BMC Infect Dis 2019; 19:119 doi:10.1186/s12879-018-3655

7. Gunasekara T, Velathanthiri V, Weerasekara M, et al. Knowledge, attitudes and practices regarding dengue fever in a suburban community in Sri Lanka. Galle Medical Journal 2012; 17(1):110-17. doi: http://dx.doi.org/10.4038/gmj.v17il.4355

8. Agampodi SB, Agampodi TC, Thalagala E, et al. Do people know adequately about leptospirosis? A knowledge assessment survey in post-outbreak situation in Sri Lanka. Int J Prev Med. 2010; 1(3):158-163 PMID: 21566785 PMCID: PMC3075525

9. Sarwankar A, Mulla S. Prevalence of leptospirosis in various risk groups of South Gujarat, India. International Journal of Advances in Science Engineering and Technology. 2017; 5(2):53-5. No doi

10. Arbiol J, Orencio PM, Nomura H, et al. Knowledge, attitude and practices towards leptospirosis among lakeshore communities of Calamba and Los Baños, Laguna, Philippines. Agriculture. 2016; 6(2):18. doi: https://doi.org/10.3390/agriculture6020018

11. de Araújo WN, Finkmoore B, Ribeiro GS, et al. Knowledge, attitudes, and practices related to leptospirosis among urban slum residents in Brazil. Am J Trop Med Hyg. 2013; 88(2):359-63. doi:10.4269/ajtmh.2012.12-0245

12. Abiayi E, Inabo H, Jatau E, et al. Knowledge, attitudes, risk factors and practices (KARP) that favor Leptospira infection among abattoir workers in North Central Nigeria. Asian Journal of Epidemiology. 2015; 8(4):104-113 doi: 10.3923/aje.2015.104.113

13. Quina CR, Almazan JU, Tagarino JB. Knowledge, attitudes, and practices of leptospirosis in Catbalogan City, Samar, Philippines. American Journal of Public Health. 2014; 2(3):91-8. doi: 10.12691/ajphr-2-3-5

14. Brett Major DM, Lipnick RJ. Antibiotic prophylaxis for leptospirosis. Cochrane Database of Systematic Reviews 2009; 3: Art. No:CD007342. doi: 10.1002/14651858

15. Prabhu N, Meera J, Bharanidharan G, et al. Knowledge, attitude and practice towards leptospirosis among municipal workers in Tiruchirapalli, India. International Journal of Pharma Research and Health Sciences. 2014; 2(3):246-254. No doi 